\title{
O PROCESSO DE BOLONHA E SUAS CONSEQÜÊNCIAS NA ITÁLIA
}

\author{
Cássio Ricardo Fares Riedo \\ Elisabete Monteiro de Aguiar Pereira
}

\section{RESUMO}

A declaração assinada na Universidade de Bolonha em 1999 por alguns ministros da União Européia responsáveis pela instrução superior representa o que ficou conhecido como "Processo de Bolonha". Contudo é possível considerar sua origem já presente no Tratado de Maastrich de 1992, que originou a União Européia, ou, mais recentemente, na Convenção de Lisboa de 1997, que discutiu o reconhecimento de títulos superiores nos diferentes Estados europeus. O processo transcendente o encontro de Bolonha, pois houve uma reunião preparatória em Paris (1998) e continuou em sucessivos encontros ocorridos em Praga (2001), Berlim (2003) e Bergen (2005). O objetivo declarado foi construir até 2010 um Espaço Europeu de Instrução Superior que assegurasse a qualidade na formação a fim de tornar as universidades européias competitivas diante do processo de internacionalização e desenvolvimento decorrente da globalização econômica e financeira. Na Itália, como conseqüência da adesão à declaração de Bolonha, foi proposta uma reforma universitária que buscou reestruturar o sistema de ensino superior. Este artigo procura apresentar um breve histórico do processo e sua relação com o sistema universitário italiano, analisar os objetivos declarados da reforma e mostrar alguns resultados alcançados segundo docentes e discentes através de artigos publicados por editoras italianas.

\section{PALAVRAS-CHAVE}

Universidade; Processo de Bolonha; Reforma universitária na Itália

\section{THE BOLOGNA PROCESS AND ITS CONSEQUENCES IN ITALY}

\begin{abstract}
Summary The declaration signed in the University of Bologna in 1999 for some responsible ministers of the Européia Union for the superior instruction represents what he was known as "Process of Bologna". However it is possible to consider its present origin already in the Treated one to Maastrich of 1992, that it originated the Européia Union, or, more recently, in the Convention of Lisbon of 1997, that argued the recognition of superior headings in the different European States. The process transcendente the meeting of Bologna, therefore had a preparatory meeting in Paris (1998) and continued in successive meeting occurred in Plague (2001), Berlin (2003) and Bergen (2005). The declared objective was to construct up to 2010 a European Space of Superior Instruction that assured the quality in the formation in order to ahead become the competitive européias universities of the process of internationalization and decurrent development of the economic and financial globalization. In Italy, as consequence of the adhesion to the declaration of Bologna, was proposal a university reform that it searched to reorganize the system of superior education. This article looks for to present a historical briefing of the process and its relation with the Italian university system, to analyze the declared objectives of the reform and to show to some results reached according to professors and learning through articles published for Italian publishing companies.
\end{abstract}

\section{KEYWORDS}

University; Bologna process; The reform of university in Italy 


\section{INTRODUÇÃO}

Inicialmente será apresentado um breve histórico sobre o Processo de Bolonha, considerando principalmente seu caráter político diante da adesão voluntária por parte dos países participantes (CAMOZZI, 2005; DALLA TORRE, 2006; MESSINA, 2006; SURIAN, 2006), uma vez que a declaração assinada em Bolonha era uma mais carta de intenções do que um instrumento legal, tendo sido fortemente baseada na declaração de Lisboa (1997), a qual serviu como orientação jurídica para o reconhecimento de títulos entre os Estados europeus e propunha a estruturação em ciclos e a possibilidade de transferência de créditos para facilitar o reconhecimento dos títulos e a mobilidade tanto de estudantes como de docentes (FINOCCHIETTI, 2006). Segundo Messina (2006, p.49), o processo foi indiscutivelmente de natureza política porque foi um projeto compartilhado pelos ministros responsáveis pela instrução dos paises que aderiram voluntariamente e em diferentes momentos ao processo. A compreensão do caráter político pode ser considerada importante porque, segundo Arragoni (2006, p.43), considerando que o caráter público do ensino superior foi reforçado pelo encontro de Praga (2001), os controles sobre a administração pública, e seus reflexos diretos na universidade, seriam na realidade um reflexo da relação entre o pensamento cultural e político de seu momento histórico.

Em seguida, serão apresentados alguns aspectos do sistema de educação superior italiano anteriores ao processo, pois este já era considerado em decadência e defasado em relação aos outros Estados e uma reforma era vista como necessária antes mesmo da assinatura da Declaração de Bolonha. Segundo autores como Camozzi (2005), Galesi (2005) ou Giaquinta e Guerraggio (2006), as origens dos problemas podem ser encontradas no processo histórico da organização universitária italiana, principalmente em momentos críticos como a instauração da Republica (Lei Casatti de 1861) ou durante o advento do período fascista (Lei Gentile de 1923) ou próximo à Segunda Guerra Mundial (Texto Único de 1933) ou ainda com a reforma proposta na década de 1960. Em relação à reforma dos anos 1960, que precede a atual reforma, convém ressaltar que foi caracterizada principalmente pela demanda por popularização do ensino superior, contando com a intervenção política num momento em que era buscado o Estado de Bem-Estar Social (ARRIGONI, 2006; DALLA TORRE, 2006; FELICIANI, 2006), porém permaneceram características principalmente da Lei Gentile (1923) em relação à orientação da universidade e do Texto Único (1933) em relação à sua organização, como detalhado posteriormente. 
Os resultados destas influências podem ser notados na reforma atual, que usou a adequação do sistema aos princípios assumidos nas propostas da Declaração de Bolonha como justificativa, e algumas conseqüências práticas já podem ser percebidas, como a introdução de um sistema de avaliação tanto interna quanto externa da qualidade do ensino e algumas transformações em relação à atividade docente (AMPLATZ, 2006; LA ROSA; MINGUZZI; 2005). Outro aspecto presente na avaliação foi a formação dos estudantes (CAVALLI, 2005; GUIDICINI; MANELLA, 2005) e serão apresentados alguns de seus pontos de vista e receios. Para finalizar, a conclusão será baseada, com o auxílio da citação de alguns autores, em interpretações pessoais dos aspectos levantados.

\section{ASPECTOS POLÍTICOS DO PROCESSO DE BOLONHA}

A idéia de um Espaço Europeu de Instrução Superior (EEIS), intimamente relacionado com o Processo de Bolonha, é um conceito atraente e vem sendo elaborado quase que concomitantemente com a criação da Comunidade Européia. A adesão voluntária às suas propostas pode ser considerada tanto como prova da atratividade como de seu caráter político: o documento assinado em 1999 contava com 29 paises, aumentando para 33 em 2001 na Conferência de Praga, passando a 40 na Conferência de Berlim em 2003 e chegando a 45 na Conferência de Berger em $2005^{1}$.

Os principais objetivos declarados podem ser considerados como: 1)a promoção do sistema de Instrução Superior Europeu em nível mundial, uma vez que o ensino superior, segundo Van Damme (2002 apud SURIAN, 2006, p.11), atinge cifras na ordem de 300 milhões de dólares ao ano, representando 1\% da economia mundial e 3\% do volume de trocas comerciais de serviços entre os países da Organização para a Cooperação Social e Econômica (OCDE); 2) a busca de uma harmonização entre os sistemas universitários, que facilitaria o reconhecimento de títulos de formação superior entre os países e ampliaria a oferta de mãode-obra altamente qualificada disponível no mercado de trabalho; e 3) o estimulo à mobilidade tanto de estudantes e de docentes como de profissionais entre os países participantes, propiciando o intercâmbio de experiências e conhecimentos, o que contribuiria

\footnotetext{
${ }^{1}$ Bolonha (1999): Alemanha, Áustria, Bélgica, Bulgária, Dinamarca, Eslovênia, Espanha, Estônia, Finlândia, França, Grécia, Holanda, Hungria, Islândia, Irlanda, Itália, Letônia, Lituânia, Luxemburgo, Malta, Noruega, Polônia, Portugal, Reino Unido, República Eslovaca, República Tcheca, Romênia, Suécia e Suíça; Praga (2001): Croácia, Chipre, Liechtenstein e Turquia; Berlin (2003): Albânia, Andorra, Bósnia e Herzegovina, Cidade do Vaticano, República de Macedônia (ex-Iugoslava), Rússia e Servia Montenegro; Berger (2005): Armênia, Azerbaijão, Geórgia, Moldávia e Ucrânia.
} 
para acelerar o desenvolvimento econômico e cultural de cada país. De um modo um pouco mais detalhado, Messina (2006, p.90) e Camozzi (2005, p.51) apontam que os objetivos específicos seriam: 1) sistema de títulos facilmente reconhecíveis e comparáveis; 2) sistema baseado essencialmente em dois ciclos; 3) introdução do sistema de créditos; 4) promoção da mobilidade discente e docente; 5) garantia de qualidade; e 6) promoção da dimensão européia do sistema de ensino superior.

Historicamente, apesar de, em modo restrito, o inicio da construção do EEIS ser reconhecido pelas declarações de Sorbone em 1998 e de Bolonha em 1999, o primeiro momento significativo na gênese da idéia sobre este espaço pode ser buscado na Conferência de Messina em 1955, onde os seis ministros do exterior da Comunidade Econômica do Carbono e do Aço (CECA)² decidiram estender a integração européia (COLBERT, 2005 apud MESSINA, 2006, p.49). Foi neste momento que Walter Hallstein, secretario de estado da República Federativa da Alemanha, apresentou a proposta de criar uma universidade com uma missão especifica: formar cidadãos com uma mentalidade européia e dotar-lhes de habilidades adequadas. Apesar da surpresa e das resistências causadas pela proposta, diante da exigência de criar ligações formais entre as instituições de instrução superior em direção à internacionalização, foi criada uma Conferencia Européia de Reitores que teve a primeira reunião oficial em 1959 (MESSINA, 2006, p.50).

Em 1961, presidentes e primeiro-ministros da CECA, através da Declaração de Bonn, assumiram que a cooperação deveria ir além do campo restritamente político e caminhar em direção a esfera da instrução, da cultura e da pesquisa, sendo propostos encontros periódicos dos ministros da área. Neste mesmo ano, foi publicada na Conferência permanente de ministros responsáveis pela instrução uma resolução que apontou a importância da equivalência entre os títulos universitários e a necessidade de uma melhor colaboração em relação à instrução na Europa. (MESSINA, 2006, p.51).

A Declaração de Aia em 1969 sinalou uma passagem decisiva do "Mercado Comum” diante da perspectiva de unificação política e cultural, resultando na Resolução de 1971 dos ministros responsáveis pela instrução sobre a cooperação no campo da educação, a qual indicava a necessidade de definir um modelo cultural de acordo com a integração européia e a instituição da estrutura do Centro Europeu para o Desenvolvimento da Instrução (VAN DER HARST, 2003 E WILSON, 2003 APUD MESSINA, 2006, p.51).

\footnotetext{
${ }^{2}$ Bélgica, França, Itália, Luxemburgo, Paises Baixos e Republica Federativa da Alemanha.
} 
A resolução dos ministros responsáveis pela instrução de 1974 já instituía como princípios básicos à harmonização dos sistemas de ensino através de uma melhor correspondência entre os sistemas, a intensificação na cooperação entre os institutos de ensino superior, uma melhora na possibilidade de reconhecimento dos títulos acadêmicos e dos períodos de estudo e o encorajamento da livre circulação e da mobilidade dos docentes, dos estudantes e dos pesquisadores. A Resolução de 1976 reafirmou tais princípios e acrescentou o principio da autonomia dos institutos superiores como ação prioritária para atingir os objetivos propostos. É sobre essa base que uma comissão iniciou os trabalhos para promover a harmonização dos sistemas instrucionais e definir os sucessivos planos de ações, como a "Resolução sobre o ensino superior e o desenvolvimento da cooperação universitária na Comunidade Européia”, adotada pelo parlamento europeu em 13 de março de 1984; a “Resolução sobre o reconhecimento dos títulos e dos períodos de estudo”, adotada em 14 de março de 1984; ou a "Decisão do Conselho que adota o programa de ação comunitária em matéria de mobilidade dos estudantes - Erasmus” em 15 de junho de 1987. Neste último documento se encontra uma forte motivação que conduzirá à criação da EEIS: a cultura se produz e se transmite, em primeiro lugar, nas instituições de ensino superior, sendo estas o veículo mais potente para o avanço da política da Comunidade. Concomitantemente, como produto de um simpósio de instituições universitárias ocorrido entre 5 e 6 de junho de 1987, poucos dias antes da aprovação do programa Erasmus, foi gerada a "Magna Charta Universitatum", subscrita em 18 de setembro de 1988 em Bolonha, que transcendia as motivações do programa aprovado pelo Conselho. Os reitores de 430 universidades de todo o continente declararam na "Charta” que, diante dos confrontos de todos os poderes políticos e econômicos, os princípios fundamentais que deveriam sustentar a vocação universitária seriam a autonomia, a independência moral e científica, a liberdade de pesquisa, de ensino e de formação, e a indivisibilidade entre a didática e a pesquisa (MESSINA, 2006, p.52-54).

O período posterior ao lançamento do programa Erasmus pode ser caracterizado por uma série de reuniões intergovernamentais preparatórias do Tratado da União Européia assinado na cidade holandesa de Maastricht em 1992. Os artigos 126, sobre a instrução, e 127, sobre a formação profissional, posteriormente transformados no Tratado de Amsterdam em 1997, já indicavam a direção que sintetizaria os fundamentos do Processo de Bolonha: dimensão européia da instrução, mobilidade, reconhecimento dos títulos e dos períodos de estudo, cooperação entre os institutos de ensino e troca de informações e experiência. Para finalizar a apresentação "histórica”, dois outros documentos representaram e anteciparam as 
pilastras do EEIS: a "Convenção sobre o reconhecimento dos títulos relativos ao ensino superior na região européia”, promovida pelo Conselho da Europa e pela UNESCO e aprovada em 11 de abril de 1997 em Lisboa; e o documento que definia recomendações do Conselho da União Européia, de 23 de setembro de 1998, intitulado “Cooperação européia para a garantia da qualidade na instrução superior” (MESSINA, 2006, p.54-56).

\section{O CONTEXTO ITALIANO ANTES DA REFORMA}

De modo geral, mantendo uma abordagem com caráter político, Giaquinta e Guerragio (2006, p.25) apontam que a reforma na Itália foi guiada por uma idéia de universidade e de sociedade de acordo com posições de centro-direita, tendo sido introduzida por um governo de centro-esquerda e implementada pela centro-direita, com resistências na Universidade de posturas supostamente tendendo à centro-esquerda (FARES RIEDO, 2006, p.194-202). Para compreender melhor o contexto italiano, de modo semelhante à evolução histórica sobre a formação do EEIS, será apresentado um breve histórico da organização do sistema universitário italiano com a motivação de auxiliar a percepção da relação entre os aspectos político-culturais e o Processo de Bolonha, começando a abordagem a partir de um importante momento histórico que foi a proclamação da unidade nacional, reconhecida oficialmente em 17 de março de 1861.

Segundo Galesi (2005, p.14-16), em 1861, havia 20 universidades na Itália diante de uma taxa de analfabetismo de 75 a $80 \%$ contra 20 a 30\% na Inglaterra e 40 a 50\% na França (Giaquinta e Guerragio, 2006, p.15). Tal quantidade de universidades seria absolutamente desproporcional tanto em relação à população quanto aos outros países europeus, além de ser fruto mais de fatores políticos, como compromissos com as instituições e ordens eclesiásticas ou pelo prestigio cultural de cada região, do que da efetiva necessidade de recobrir os postos de direção do sistema econômico-cultural do território. O primeiro ato constitutivo da política universitária promulgado pelo Estado unificado foi a Lei Casatti que, "para garantir uma adequada preparação de caráter tanto cultural quanto técnico-profissional”, procurou regular a vida universitária em seus mínimos detalhes, fixando não apenas o número de instituições, porém sem diminuir sua dimensão, como também a organização interna e as características da carreira docente, configurando um sistema decididamente centralizado, com autonomia limitadíssima e quase nenhuma liberdade de ensino.

Galesi (2005, p.17-18) aponta ainda que, diante da Lei Casatti que não definia claramente a missão da formação universitária segundo uma orientação cultural ou 
profissionalizante, em 1923, já no período fascista, a reforma Gentile impôs uma formação com função primeiramente cultural e secundariamente profissional, introduzindo o exame de Estado, mantido até os dias atuais, após o final do curso para verificar a aplicabilidade e utilização do conhecimento aprendido durante a formação e controlar a inserção profissional. Foram abolidos planos de estudos rígidos e ampliada a autonomia didática das universidades, além de eliminar os exames no final de cada curso, deixando-os obrigatórios apenas por grupo de disciplinas. Mesmo com uma maior articulação nos critérios de acesso e com o aumento da autonomia didática e administrativa, o sistema continuou seletivo, fortemente elitizado e centralizado, tendo sido introduzidas a diferenciação entre as funções de professor e assistente e a redução do espaço de representação nos órgãos colegiados.

Nos anos 30, como também apontado por Giaquinta e Guerragio (2006, p.12), o Texto Único de 1933 e vários outros procedimentos sucessivos dos ministros De Vecchi e Bottai, as autonomias administrativa, didática e disciplinar, ainda que parciailmente reconhecidas pela reforma Gentile, foram reconduzidas à estreita vigilância do Estado e os currículos e planos de estudo passaram a ser novamente regulamentados através da classificação de disciplinas fundamentais e complementares para cada curso e da imposição do número de exames para a obtenção dos títulos, além de acentuar a vocação profissionalizante dos estudos universitários e de deixar em segundo plano a orientação "puramente científica”.

Segundo Giaquinta e Guerragio (2006, p.12), a realidade universitária começou a manifestar concretamente certa propensão à mudança somente na metade dos anos 1960 e a reforma, diante da demanda pela popularização do ensino superior, permitiu o ingresso de todo estudante que tivesse concluído a etapa anterior do sistema de ensino ${ }^{3}$, sem passar por nenhum critério que pudesse restringir a entrada na universidade (FARES RIEDO, 2006, p.90). Contudo, segundo Camozzi (2005, p.47), a reforma era destinada à falência porque foi realizada com procedimentos ainda vinculados ao Texto Único de 1933 e, embora no resto da Europa ocidental os sistemas de ensino vinham sendo diversificados através do alargamento da oferta formativa pós-secundária não universitária, a Itália manteve invariadas as características organizativas e estruturais do sistema de instrução superior.

Giaquinta e Guerragio (2006, p.13) apontam como problema grave de então a distância abissal entre docentes e estudantes e a grande dificuldade de compreender, não tanto os conteúdos de cada curso, mas a trama geral, o significado e a potencialidade do

\footnotetext{
${ }^{3}$ Chamado na Itália de “ensino superior” e equivalente ao “ensino médio” brasileiro.
} 
pensamento abstrato, sendo que, apesar da suposta abertura da universidade a todos os estudantes interessados, a seleção acontecia na passagem do primeiro ao segundo ano de estudo. Para Galesi (2005, p.41), diante de dados como o de 1999, a Itália, com uma média de 33 estudantes para cada docente (Alemanha, 13; Estados Unidos, 15; Inglaterra, 18; França, 24), com seu sistema de gestão centralizada, não soube como enfrentar o aumento da população estudantil com um coerente aumento no recrutamento de docentes, principalmente devido à expansão descontrolada que a eliminação na seleção provocou (FARES RIEDO, 2006, p.89-90).

Como ponto positivo, Giaquinta e Guerragio (2006, p.15-21) vêem o aumento no percentual de jovens de 19 anos matriculados que passou de 19,0\% em 1971 para 41,7\% em 1992, melhorando o confronto com outros países europeus (Alemanha, 47,8\%; França, 47,9\% e Inglaterra, 36,9\%). Porém, mesmo diante deste acentuado aumento, usando o curso de matemática como indicativo das ciências exatas, as matrículas caíram de 4674 no ano letivo de 1990-1991 a 1611 em 2000-2001, aumentando em 2005-2006 de modo pouco significativo para 2094 (entre 0,6 e 0,7\% do total de matrículas). Segundo estes autores, a baixa procura pelos cursos da área científica revelaria um fenômeno com raízes em sérios problemas estruturais da sociedade italiana. Tal fenômeno, nem sempre compreendido ou reconhecido em sua gravidade, estaria associado ao declínio industrial, mesmo depois do fim do sistema de participação estatal, à pulverização das empresas, à especialização e à baixíssima presença de uma cultura da inovação nas empresas e mesmo na universidade. Contudo, não relacionam tais problemas com a postura da universidade voltada para a cultura clássica e que deixava a formação “puramente científica” em segundo plano. Porém, conforme Scalera, Caponera e Russo (2006, p.57), seria indicativo do histórico atraso da Itália no campo da cultura e da pesquisa, principalmente em relação à avaliação didática e particularmente no nível superior. Para Paganetto (2006, p.38), a universidade e a pesquisa estariam mudando muito lentamente, sendo necessário adequar o sistema nacional de pesquisa aos procedimentos e aos instrumentos de avaliação já em uso em outros países.

Segundo Giaquinta e Guerragio (2006, p.29-30), a universidade italiana pré-reforma, com sua postura arcaica e enrijecida, como resultado da sobrevalorização da formação cultural, não conseguia mais dialogar com os novos mapas dos saberes e de suas interações, tendo sido julgada por uma suposta baixa produtividade como conseqüência do forte autoreferenciamento e da propensão à marginalização diante das demandas do mundo econômico, vindas tanto das indústrias e dos serviços quanto da administração pública. Reforçando a 
mesma interpretação, La Rosa e Minguzzi (2005, p.89) apontam que a reforma tentou intervir substancialmente sobre um sistema formativo que se tornou rígido e reconhecidamente incapaz de responder às exigências de uma sociedade em rápida transformação, enfrentando os problemas históricos da universidade italiana: 1)alto coeficiente de dispersão e de abandono; 2)baixo percentual de conclusão no tempo previsto; 3)pouca flexibilidade na organização dos cursos; e 4)incapacidade de responder de modo articulado e eficaz ao mundo do trabalho.

De modo quantitativo, os problemas apontados eram: 1)dois a cada três estudantes não concluíam os cursos iniciados, apresentando em 2000 uma taxa de abandono de 21,4\% em relação à passagem do primeiro ao segundo ano de estudo (CAMOZZI, 2005, p.55), que estaria gerando embaraços psicológicos, frustração, baixa auto-estima e desvalorização cultural; 2)tempo de estudo muito além dos quatro anos previstos para a finalização dos cursos, que elevava a idade média na conclusão para 25,8 anos em 2000 (CAMOZZI, 2005, p.55), tornando-a superior a de outros países europeus; 3)validação de títulos para o ingresso no mundo do trabalho idênticos à um passado remoto, baseado principalmente no título de láurea universitário. Scalera, Caponera e Russo (2006, p.58) apontam ainda deficiências na integração entre os componentes do currículo, principalmente na conexão entre os diferentes formatos didáticos e Camozzi (2005, p.52-53) afirma que, diante de um aumento de matrículas na ordem de $700 \%$ nos últimos 50 anos, com as atuais 75 instituições de ensino superior distribuídas em 180 cidades $^{4}$, a qualidade do sistema universitário italiano não parece ter acompanhado o crescimento quantitativo, sendo necessária uma modificação profunda que consiga conciliar tanto a quantidade quanto a qualidade na oferta formativa.

Diante de um modelo econômico que estaria conduzindo o país à marginalização, mas não necessariamente a pobreza, e de preocupações por um sistema formativo que parecia resignado e adaptado ao declínio (GIAQUINTA; GUERRAGIO, 2006, p.22), Stefani (2006, p.136) apontou a exigência das universidades italianas de incrementarem a própria eficiência e de melhorar os serviços prestados aos estudantes a fim de recuperar competitividade no mercado interno europeu da formação profissional. Segundo Giaquinta e Guerragio (2006, p.31), considerando a inércia do mundo universitário, baseada no conservadorismo cultural, na falta de estímulos e em interesses corporativos e econômicos, nada se podia esperar da

\footnotetext{
${ }^{4}$ Segundo dados oficiais seriam 76 instituições públicas e 33 privadas em 2002 (FARES RIEDO, 2006, p.88).
} 
própria universidade de concreto e de determinado em relação a transformações, sendo o único modo impor uma reforma do alto, suficientemente mimetizada.

\section{A REFORMA: CICLOS, CRÉDITOS, MOBILIDADE E RECONHECIMENTO DE TÍTULOS}

Em relação à reforma, Cammelli (2005, p.9) afirma que esta redesenhou a oferta formativa, prevendo uma nova articulação em três ciclos e assumiu objetivos ambiciosos como uma maior difusão de títulos universitários na população, redução na taxa de abandono, diminuição no tempo de permanência dos estudantes na universidade, aproximação ao mundo do trabalho e internacionalização dos percursos de estudo através da implantação de créditos formativos para torná-los comparáveis aos obtidos em diferentes cursos e universidades. La Rosa e Minguzzi (2005, p.79) confirmam que a reforma provocou e tem provocado modificações organizativas altamente relevantes sobre a oferta formativa, pondo cada vez mais ênfase em conceitos de competência, flexibilidade e empregabilidade. Pesenti (2005, p.131) aponta para uma abertura progressiva a um modelo em que concorram sujeitos públicos e privados, indicando alguns pontos ainda necessários: 1) a descentralização; 2) o incentivo a novas universidades; 3) a introdução de subsídios à requisição e não diretos; 4) a eliminação de regulamentos inúteis; e 5) a promoção da concorrência internamente a União Européia. Arragoni (2006, p.48) reforça a estreita lógica da eficiência, a qual assumiu relevo ao condicionar os financiamentos, sejam públicos ou privados.

A atual reforma, justificada pela adequação do sistema italiano às propostas da declaração de Bolonha, ficou conhecida popularmente como "sistema 3+2" devido a duração do primeiro ciclo, no qual é obtida a "laurea trienal”, com duração de três anos, e do segundo ciclo com duração de dois anos, no qual se obteria a "laurea especialística”, havendo a possibilidade de continuar a formação científica num terceiro ciclo através do "dottorato di ricerca”. De um ponto de vista prático, foi implantado o sistema de créditos formativos universitários (CFU), com o equivalente de um crédito para cada 25 horas de atividade educativa; os cursos foram reestruturados para se adequarem aos ciclos propostos, alterando o rígido currículo anterior diante da possibilidade de cada universidade determinar até $40 \%$ do próprio currículo, devendo seguir os 60\% restantes determinados pelo Ministério da Universidade e Pesquisa Tecnológica; e alguma autonomia financeiro-didática foi concedida às universidades, como a administração dos fundos baseados na quantidade de estudantes matriculados e a possibilidade de determinar a relação entre créditos e atividades educativas e 
a forma de avaliação das disciplinas não reguladas oficialmente (FARES RIEDO, 2006, p.9394). Contudo, considerando a publicação do principal decreto sobre a reforma (DM 509) e a implantação dos cursos praticamente no mesmo ano letivo, percebe-se o modo apressado e pouco refletido na condução desta e o curto período para discussão, que já vinha acontecendo mesmo antes da publicação oficial da reforma, diante de incentivos econômicos governamentais para a ativação inicial dos primeiros ciclos da reforma.

Analisando alguns aspectos práticos, para La Rosa e Minguzzi (2005, p.91), o sistema de créditos seria uma unidade de medida estandardizada da experiência cognitiva assimilada em ordem e formas diversas, baseado sobre a dedicação total dos estudantes, e não apenas sobre as horas de aulas diretas, facilmente reutilizáveis no âmbito do sistema universitário. Porém, segundo Giaquinta e Guerragio (2006, p.48-49), ocorreu uma subordinação à uma lógica produtivista, onde o momento do estudo e todo o ciclo trienal tornou-se apenas um parênteses, nada divertido, antes de chegar ao mundo do trabalho, valorizando a visão que a universidade estaria ultrapassada, que o estudo teria pouca ou nenhuma utilidade e seria uma perda de tempo diante da escola verdadeira, que seria a vida. Considerando que o mercado tende a favorecer a formação profissional e a aplicação prática do conhecimento (GIAQUINTA; GUERRAGIO, 2006, p.58), tal visão de universidade e posicionamento político estaria levando a um redimensionamento do momento teórico, penalizando-o, subavaliando-o, marginalizando-o e comprometendo toda na formação universitária e o futuro dos jovens.

Paganetto (2006, p.39) afirma que, diante de fenômenos produzidos pela introdução do “sistema 3+2", como a proliferação da oferta didática, a universidade, posta diante da necessidade de atrair estudantes além do próprio território, começou a produzir uma tipologia muito diferenciada de oferta, talvez demais diferenciada, e de difícil avaliação, sugerindo que esta deveria se orientar por um modelo similar ao anglo-saxão como o implantado em outros países como a Holanda. La Rosa e Minguzzi (2005, p.90) apontam a estreita conexão entre os conceitos de autonomia, flexibilidade, responsabilidade e avaliação, trazendo como conseqüência a irracional proliferação de cursos, onde uns efetivamente mostraram um profundo repensar da estrutura e dos conteúdos da formação universitária, mas outros foram introduzidos exclusivamente numa lógica meramente acadêmica, fundada em interesses de alguns docentes que detinham uma posição de poder ao interno das faculdades ou em base na capacidade de atrair estudantes interessados em mais modismos do que na própria vocação. Além de tudo, Giaquinta e Guerragio (2006, p.51) apontam para a oferta de um produto de 
baixa qualidade que apenas posterga o momento da seleção no mercado de trabalho, dominado mais pela tradição e por contatos familiares do que pela formação recebida.

Juntamente com as críticas, convém ressaltar outros pontos das reuniões posteriores a Bolonha e Messina (2006, p.91) aponta que, além da idéia fundamental de promover a empregabilidade permanente dos cidadãos europeus e a competitividade internacional do sistema de ensino superior, em Praga (2001), reforçou-se a idéia de universidade como bem público e que deverá permanecer sob responsabilidade pública, baseando-se em princípios como a autonomia institucional, a participação dos estudantes nos órgãos governamentais de instrução superior e a cooperação e confiança entre os países participantes e organizações. Em Berlim (2003) foram acrescidos novos conceitos como o terceiro ciclo e a função dupla tanto de preparar os estudantes para o mercado do trabalho quanto de desenvolver ulteriores competências. Foram incentivados também o desenvolvimento de dispositivos nacionais de garantia da qualidade e o reconhecimento de títulos como proposto pela Convenção de Lisboa, único empenho legal em todo processo.

\section{CONSEQÜÊNCIAS DA REFORMA: O SISTEMA DE AVALIAÇÃO E OS DOCENTES}

Um ponto relevante ressaltado por Messina (2006, p.68-69) é como a criação do EEIS se relaciona com a necessidade de assegurar a qualidade de formação nas diferentes universidades através de um movimento de cooperação pela garantia da qualidade em dimensão mundial. Segundo Paganetto (2006, p.38), a consciência da importância do valor da autonomia, que seria seguramente essencial, deveria ser suportado também por uma cultura de avaliação dos resultados, como conceito fundante da mesma idéia de autonomia. Semeraro (2006, p.9-10) aponta que a reforma reforça o papel da avaliação externa à universidade, deixando-a a cargo de agencias nacionais alinhadas às orientações européias e internacionais, originadas em importantes organismos como a UNESCO, a OCSE, a OMC ou o Banco Mundial. Surian (2006, p.23-39) comprova a argumentação de Semeraro comparando as orientações dos organismos internacionais com as propostas italianas sobre a avaliação do ensino superior através da análise de seus documentos.

Como conseqüência das transformações estruturais nas quais a atividade docente passou a ser também objeto de avaliação, La Rosa e Minguzzi (2005, p.84-85) consideram imprescindível à profissionalidade do docente, exprimir-se em nível técnico-especialista além de compreender o papel e a função que a universidade exerce na sociedade do conhecimento, 
tornando-o capaz de contribuir e atualizar, transmitir eficazmente e repensar criticamente as temáticas do objeto de ensino e do conhecimento da estrutura da disciplina, consciente do significado cultural, epistemológico, científico e social do saber. Porém, na Itália, segundo D’Atena (2006, p.24), o regulamento 270/2004, que substituiu o DM 509/1999 e o DM de 04/10/2000, prevê que as funções didáticas sejam atribuídas aos professores e pesquisadores ano a ano, substituindo a titularidade da cátedra pela titularidade do setor científicodisciplinar, com possível conseqüência do uso das atribuições anuais como instrumento de condicionamento dos docentes, de transformar o que deveria ser uma escola de liberdade em uma escola de conformismo.

Ainda assim, para La Rosa e Minguzzi (2005, p.81-83), a constante atualização dos conteúdos não poderia prescindir de uma precedente atividade de documentação e pesquisa, que conduziria a um enriquecimento crítico e consciente do conhecimento da disciplina, capaz de adaptar a atividade didática a situações complexas nas quais ocorreria também a prática. Tornou-se vital a reflexão sobre como ensinar, porque ensiná-la em sua globalidade e em seus vários aspectos, além de conhecer as características da platéia destinatária e de outros professores a fim de tornar a oferta formativa mais homogênea e abrangente possíveis, de transformar o ensinamento em aprendizagem, fazendo com que o discente aprenda não apenas o conteúdo da disciplina mas também o modo como aprender. Enfim, a ampliação das exigências formativas da docência requer a atribuição ao indivíduo de motivações, responsabilidades e lógicas na constituição da própria identidade profissional, pressupondo em primeira instância a responsabilização do indivíduo-docente, feita de momentos individuais e também coletivos de formação, vividos em primeira pessoa e consciente do próprio crescimento profissional (LA ROSA; MINGUZZI, 2005, p.87).

\section{CONSEQÜÊNCIAS DA REFORMA: PONTO DE VISTA E RECEIOS DOS ESTUDANTES}

Outro ponto considerado na avaliação é a opinião dos estudantes e para compreender seus pontos de vista e receios foram considerados artigos que comentaram a avaliação através do resultado da aplicação de questionários em estudantes. Nos estudos de Pesenti (2005, p.133-144), relacionou-se a reforma ao valor legal dos títulos e ao direito ao estudo, incluindo também a seletividade na universidade, buscando auferir como os estudantes se sentem afetados pela reforma. Amplatz (2006, p.140-157) analisou opiniões coletadas sobre a qualidade do ensino e como os estudantes sentiram a reforma, questionando principalmente o 
que saberão e o que saberão fazer ao fim dos estudos; se aquilo que aprendem é necessário, suficiente e útil; se o processo educativo foi eficiente; e se as promessas da instituição foram cumpridas. Em Guidicini e Manella (2005, p.150-158), foram detalhadas, através de perguntas qualitativas, a interpretação dos estudantes sobre a iniciativa de aproximar a universidade às exigências do território, sobre as idéias a respeito da universidade depois de terem iniciado seus cursos, sobre os pontos fracos do curso segundo sua organização e segundo a didática e o ensino, sobre as vantagens do "sistema 3+2" e sobre como tornar a universidade italiana mais competitiva em relação aos outros Estados europeus.

Porém, antes de comentar os estudos dos questionários é oportuno ressaltar o documento criado pela Assembléia dos Estudantes e apresentado por Camozzi (2005, p.7077) sobre o posicionamento destes em relação à reforma. Consta no documento que o “sistema 3+2" foi interpretado de maneira distorcida, tendo sido propostos percursos formativos ou excessivamente profissionalizante ou excessivamente genéricos, fruto da compressão dos cursos anteriores ao novo sistema, com uma conseqüente redução na qualidade da oferta formativa e sem uma redução efetiva na carga didática. Continuaria também faltando mobilidade ao sistema entre o triênio e o biênio e entre as universidades. $\mathrm{O}$ sistema de créditos foi usado por uma parte dos docentes como tentativa de manter espaços de poder e continuar sobrevalorizando a própria disciplina em relação às outras. De modo geral, os estudantes foram constritos a dedicar-se mais a exames que propiciam mais créditos, sem poder se aprofundarem em disciplinas de maior interesse pessoal. Outro problema em relação aos créditos seria a atribuição feita de acordo com a dificuldade do exame e independente da nota e do nível de preparação individual, sendo atribuída a mesma quantidade de créditos para todos os estudantes aprovados. Além disso, a seleção inicial e as verificações contínuas não teriam trazidas o resultado esperado pelo ministério de diminuir o tempo de obtenção dos títulos de estudo, mas teriam apenas aumentado a dificuldade em obtê-los.

O documento ainda põe como necessidade dos estudantes uma melhor orientação desde a realização da matrícula até a elaboração da tese e a entrada no mercado de trabalho; uma avaliação qualitativa da didática; mais espaço para a discussão sobre os objetivos da formação, os conteúdos dos cursos e créditos para renovar a didática aplicada, relançando a necessidade e o valor da didática interativa e auto-gestida para personalizar o percurso de estudo; autonomia para decidir o percurso formativo; redefinição das regras e dos direitos dos estudantes; o caráter público e a finalidade social da universidade; uma maior mobilidade 
nacional e internacional; o fim da seleção inicial; e a disponibilidade de residência e condições de vida e de assistência para os universitários.

É apontada ainda a quantidade insuficiente de docentes e mesmo de infra-estrutura diante da proliferação dos cursos trienais, a insuficiência na estrutura diante da obrigatoriedade da freqüência, a falta de preocupação com os estudantes trabalhadores que seriam um terço do total de estudantes e precisariam ser consideradas a diversificação no horário, a possibilidade de cursos noturnos e a flexibilização nos métodos e momentos de provas e exame. Foi citada também a possibilidade da ingerência de empresas privadas na organização e gestão dos cursos com a progressiva desvalorização das faculdades humanísticas devido à inevitável diminuição no financiamento em decorrência da não aplicabilidade prática e imediata diante das exigências do mercado econômico. Outro aspecto relacionado à diversificação das instituições de ensino é quanto aos cursos de formação profissional privados, certamente mais caros, que não deveriam ser equiparados à preparação universitária, pois, além de favorecer o poder econômico, tenderiam a diminuir ainda mais a qualidade do ensino nas universidades através de comparações possivelmente distorcidas. Diante de tantos pontos problemáticos e da necessidade de reestruturação nas instituições universitárias, os estudantes definiram a atual reforma como incompleta e realizada de modo distorcido.

Uma modificação pós-reforma em relação à postura dos estudantes apontado por Giaquinta e Guerragio (2006, p.59), não se referindo apenas à avaliação, foi quanto aos créditos e à lógica de mercadoria do conhecimento, em decorrência da qual os alunos passaram a recusar qualquer atividade de estudo que não seja imediatamente avaliada e retribuída em termos de créditos. Mais especificamente em relação à avaliação, Amplatz (2006, p.160-161) reconheceu nos estudantes um sentimento de inutilidade e de descrença nos eventuais efeitos positivos da avaliação, que pôde ser percebido pelo inserindo de insolências e impropérios nos questionários, provavelmente em decorrência do anonimato e também da frustração de não se sentirem como protagonista do processo formativo, relegados ao papel de meros respondentes da aplicação.

Segundo Pesanti (2005, p.144), há, em geral, um juízo negativo sobre a reforma que corresponderia a uma indisposição à abertura a uma nova fase da universidade, apesar de, segundo Guidicini e Manella (2005, p.163), os estudantes inscritos no novo sistema terem dado juízos positivos mais elevados sobre as várias possibilidades oferecidas pela nova ordem, apreciando a menor duração do curso e a maior rapidez de acesso ao mundo do 
trabalho, solicitando uma maior profissionalidade do corpo docente e apontando críticas específicas sobre a docência universitária.

Concluindo, emerge, de modo geral, uma imagem substancialmente conservativa e um juízo negativo sobre a reforma. Porém, segundo Guidicini e Manella (2005, p.144-146), o fechamento protecionista detectado nos estudantes poderia ser reflexo do medo diante da transformação acentuada no paradigma conhecido e, diante da ausência de consciência sobre direitos coletivos ligada a capacidade nem sempre linear de apoiar as escolhas sobre justificativas racionais, apenas confirmaria a imagem de uma população estudantil com baixa capacidade reflexiva. Mas, enquanto autor deste artigo, me pergunto e deixo em aberto qual seria a responsabilidade dos docentes diante de tal imagem negativa e o que deveria ser feito para que a formação universitária conseguisse, como imagino que seria função da universidade, desenvolver tal capacidade reflexiva, que, diante do documento apresentado pela Assembléia dos Estudantes, não me parece tão baixa.

\section{CONSIDERAÇÕES FINAIS}

A Universidade, seja ela qual for, como for ou onde for, só tem sentido se considerada a relação de ensino e aprendizagem e a interação entre docentes e estudantes. E' através desta interação que tanto estudantes como docentes podem evoluir tanto como profissionais ou pesquisadores quanto como indivíduos. Na busca da evolução pessoal, que também apresenta reflexo social, a universidade deve servir como um lugar livre de restrições políticas momentâneas para a criação de novas idéias e o desenvolvimento cultural. Considerando a universidade nesta perspectiva, o Processo de Bolonha, que em suas declarações busca valorizar e ampliar a qualidade na formação superior das novas gerações, tem aspectos positivos que não podem ser minimizados, como o incentivo à mobilidade e ao reconhecimento dos títulos entre os diversos Estados. Há pontos que precisam ser discutidos e melhor compreendidos, como a concorrência entre os estabelecimentos de ensino e o método de avaliação interna e externa de cada universidade. Outros pontos, baseando-se nos princípios da própria universidade, precisam ser questionados, como uma possível submissão da formação ao mercado de trabalho. Enfim, para superar as dificuldades impostas por uma mudança paradigmática na estrutura da Universidade, através de reformas necessárias para atualizar os vínculos sociais, deve-se considerar principalmente os atores mais próximos e interessados nos frutos do próprio trabalho: docentes e estudantes. 
O problema, segundo Giaquinta e Guerragio (2006, p.70-71), é que não se compreende mais em que consiste a missão da universidade e parece que, na verdade, ninguém quer saber; mas, se houvesse um acordo sobre os objetivos primários a seguir, seria muito mais fácil a discussão sobre a seleção de estudantes, o recrutamento de docentes e pesquisadores ou outros aspectos organizativos da vida universitária. É um problema complexo que não se resolve simplesmente com a assinatura de contratos ou com o cancelamento de algumas normas consideradas restritivas ou confiando simplesmente nas leis do mercado. Do ponto de vista financeiro, um dos problemas, segundo Stefani (2006, p.129), é que o controle das despesas não é mais confiado a controles de legitimação de tipo formal, mas centrado principalmente sobre verificações de eficácia e de eficiência, na tentativa de passar de uma lógica contábil baseada em autorizações a uma lógica econômica capaz de possibilitar a análise de custos e rendimentos. Para Arragoni (2006, p.45), o sistema universitário, que nunca foi totalmente dissociado da função instrumental, continua visto como serviço do Estado e sob sua tutela, mostrando dificuldade em absorver a autonomia reconhecida na constituição (art.33) e a proteção de valores congênitos aos princípios de liberdade de pensamento, de cultura e de ciência, princípios fundamentais de qualquer ordenamento democrático. E não se pode deixar de considerar, como apontado por Giaquinta e Guerragio (2006, p.39), que a possibilidade de ascender aos estudos universitários permanece um privilégio quase exclusivo das classes sociais mais elevadas, onde apenas 5,4\% dos jovens provenientes de uma classe social inferior conclui o curso contra um percentual de 32,1\% dos filhos da burguesia, parecendo que não seja suficiente oferecer a possibilidade formal de acesso ao aparato universitário.

Arragoni (2006, p.57) coloca que, na realidade e apesar dos discursos, a autonomia da universidade estaria sendo comprimida, numa tendência contra a lógica das reformas dos anos 1990 de separação entre o endereçamento político e as atividades de gestão, percebendo-se sinais de um dirigismo e centralismo decisionais, com programas avaliados trienalmente pelo ministério, de modo discriminante não apenas em relação à alocação dos fundos a favor das universidades, mas também em relação às escolhas organizativas, diante da contínua erosão dos recursos designados. Segundo Stefani (2006, p.141-142), o sistema de financiamento seria caracterizado por um modelo altamente centralizado, no qual a divisão dos recursos não seria mais feita através de parâmetros quantitativos mas baseado na avaliação ministerial ao plano trienal apresentado pelas universidades. Deste modo, caberia ao ministério definir os objetivos do sistema universitário para que cada universidade estabelecesse seu plano trienal e 
o ministro e seus assessores confrontariam os planos, decidindo a melhor forma de alocar os recursos entre as universidades. Entretanto, num sistema baseado em um modelo estruturalmente orgânico e procedimentalizado como o italiano, não é possível confrontar seriamente os objetivos contidos nos diversos programas e a alocação de recursos torna-se, na realidade, pura negociação política. E, em tal contexto, a planificação passaria a ser percebida como atividade ritual e inútil, mais destinada a promessas do que à avaliação racional das diversas alternativas.

Para La Rosa e Minguzzi (2005, p.93) existem ainda os riscos de uma desqualificação cultural e de uma profissionalização precoce, diante da marginalização da atividade de pesquisa, da rigidez das tabelas e classes de cursos e do incerto reconhecimento do valor legal dos títulos de estudo, sendo necessário, como afirmado por Giaquinta e Guerragio (2006, p.74-75), reconhecer a diversidade na formação universitária, admitindo que a profissionalização e a formação superior são objetivos diversos que pressupõe sensibilidades e escolhas culturais e organizativas diferentes, evitando o risco de tentar alimentar uma cultura unitária que não transmita mais nada. Porém, como apontado por Scalera, Caponera e Russo (2006, p.59), é preciso considerar a mudança no paradigma pedagógico caracterizado pela passagem do conceito baseado na transmissão e aceitação passiva do conhecimento para um conceito de promoção e facilitação da aprendizagem, onde os conteúdos aprendidos (conhecimento, competência, relações) são frutos de um processo de construção ativa numa rede de significados relevantes a nível pessoal e negociados em contextos culturais e sociais “process/student oriented instruction”), como mostrado por Bruner (1996) ou Brown, Collins e Duguid (1989). Mas, sobretudo, como afirmado por Giaquinta e Guerragio (2006, p.61-62), deve haver um projeto e um modelo de universidade e assumir a responsabilidade por tal escolha, apesar de ser mais fácil se impacientar e dizer que não se consegue fazer reformas na Itália e que o mundo acadêmico é refratário a qualquer inovação que toque os próprios privilégios e deixar a possibilidade de escolha a cada universidade, reconhecendo a falência da política e permitindo que se confie em um regulador externo e supostamente objetivo, pois, segundo Amplatz (2006, p.161), é difícil crer que o Sistema Nacional de Avaliação, prosseguindo na linha atual, favorecerá um desenvolvimento real da qualidade dos processos formativos.

Enfim, existem perspectivas animadoras e constatações preocupantes, o Processo de Bolonha continua e reformas vão sendo realizadas em vários Estados. Compreender o passado, relacioná-lo com o presente e projetar o futuro fazem parte do desenvolvimento 
cultural e, se as universidades ainda têm a pretensão de serem instituições sociais relevantes, todos os conceitos discutidos devem ser esclarecidos e devidamente relacionados para que se possa estabelecer um projeto que ultrapasse interesses políticos imediatos e que sirvam realmente à toda a sociedade.

\section{REFERÊNCIAS}

AMPLATZ, C. La valutazione istituzionale della didattica universitaria in Italia. In: SEMERARO, R. (Org.). Valutazione e qualità della didattica universitaria - le prospettive nazionali e internazionali. Milano: Franco Angeli, 2006, p.135-162.

ARRIGONI, R. Università e controlli. In: D’ATENA, A. (Org.). L'autonomia del sistema universitario paradigmi per il futuro. Torino: Giappichelli, 2006, p.43-57.

BALLONI, A. et al. La riforma universitaria nella società globale - una ricerca empirica su studenti e innovazione nei percorsi di studio. Milano: Franco Angelli, 2005, 190p.

CAMMELLI, A. (Org.). La qualità del capitale umano dell'università in Europa e in Italia. Bologna: Il Mulino, 2005, 248 p.

. La qualità del capitale umano dell'università. Caratteristiche e performance dei laureati 2003. In: __ _ (Org.). La qualità del capitale umano dell'università in Europa e in Italia. Bologna: Il Mulino, 2005, p.9-32.

CAMOZZI, A. La riforma universitaria. In: Balloni, A. et al. La riforma universitaria nella società globale - una ricerca empirica su studenti e innovazione nei percorsi di studio. Milano: Franco Angelli, 2005, p.45-77.

CAVALLI, A. Differenziare l'offerta senza rincorrere la domanda. In: CAMMELLI, A. (Org.). La qualità del capitale umano dell'università in Europa e in Italia. Bologna: Il Mulino, 2005, p.35-42.

CHIZZONITI, A. G. (Org.). Organizzazioni di tendenza e formazione universitaria esperienze europee e mediterranee a confronto. Bologna: Il Mulino, 2006, 352p.

D’ATENA, A. (Org.). L’autonomia del sistema universitario paradigmi per il futuro. Torino: Giappichelli, 2006, 142 p.

Università e costituizione. In: . (Org.). L'autonomia del sistema

universitario paradigmi per il futuro. Torino: Giappichelli, 2006, p.15-25.

DALLA TORRE, G. Università non statali e università di tendenza nell'ordinamento italiano. In: CHIZZONITI, A. G. (Org.). Organizzazioni di tendenza e formazione universitaria esperienze europee e mediterranee a confronto. Bologna: Il Mulino, 2006, p.103-117.

FINOCCHIETTI, C. Il riconoscimento dei titoli di studio in Europa - La convenzione di Lisbona. In: CHIZZONITI, A. G. (Org.). Organizzazioni di tendenza e formazione 
universitaria - esperienze europee e mediterranee a confronto. Bologna: Il Mulino, 2006, p.63-76.

FARES RIEDO, C. R. Reforma universitária e formação em psicologia: o caso da psicologia escolar e educacional na Universidade de Pádua. 2006. 349p. Dissertação (Mestrado em Educação) - Faculdade de Educação, Universidade Estadual de Campinas, Campinas, 2006.

GALESI, D. L’Università di fronte all'avvento dell'autonomia. In: Balloni, A. et al. La riforma universitaria nella società globale - una ricerca empirica su studenti e innovazione nei percorsi di studio. Milano: Franco Angelli, 2005, p.11-44.

GIAQUINTA, M.; GUERRAGGIO, A. Ipotesi sull'università. Torino: Codice, 2006, 88 p.

GUIDICINI, P.; MANELLA, G. I giudizi degli studenti attraverso l'esame di alcune domande qualitative. In: Balloni, A. et al. La riforma universitaria nella società globale - una ricerca empirica su studenti e innovazione nei percorsi di studio. Milano: Franco Angelli, 2005, p.149-163.

LA ROSA, M.; MINGUZZI, P. Riforme e docenza universitaria. In: Balloni, A. et al. La riforma universitaria nella società globale - una ricerca empirica su studenti e innovazione nei percorsi di studio. Milano: Franco Angelli, 2005, p.79-106.

MESSINA, L. Creazione dello Spazio Europeo dell'Istruzione Superiore e assicurazione della qualità. In: SEMERARO, R. (Org.). Valutazione e qualità della didattica universitaria Le prospettive nazionali e internazionali. Milano: Franco Angeli, 2006, p.47-96.

PAGANETTO, L. Economia della conoscenza: ricerca e innovazione come driver per la competività. In: D’ATENA, A. (Org.). L'autonomia del sistema universitario paradigmi per il futuro. Torino: Giappichelli, 2006, p.37-41.

PAPARELLA, N.; PERUCCA, A. (Org.). Le attività di laboratorio e di tirocinio nella formazione universitaria. Roma: Armando Ed., 2006, 288p. v. 2.

PESENTI, L. L’Università dell'autonomia, tra concorrenza e diritto allo studio.In: Balloni, A. et al. La riforma universitaria nella società globale - una ricerca empirica su studenti e innovazione nei percorsi di studio. Milano: Franco Angelli, 2005, p.131-147.

SCALERA, V.; CAPONERA, E.; RUSSO, P. M. La didattica laboratoriale nelle università italiane: uno studio esplorativo. In: PAPARELLA, N.; PERUCCA, A. (Org.). Le attività di laboratorio e di tirocinio nella formazione universitaria. Roma: Armando Ed., 2006, p.1368. v. 2.

SEMERARO, R. (Org.). Valutazione e qualità della didattica universitaria - Le prospettive nazionali e internazionali. Milano: Franco Angeli, 2006, 184 p.

. Presentazione. In: . (Org.). Valutazione e qualità della didattica

universitaria - le prospettive nazionali e internazionali. Milano: Franco Angeli, 2006, p.9-10. 
SURIAN, A. Gli orientamenti degli Organismi internazionali sulla valutazione dell'istruzione superiori. In: SEMERARO, R. (Org.). Valutazione e qualità della didattica universitaria Le prospettive nazionali e internazionali. Milano: Franco Angeli, 2006, p.11-46. 